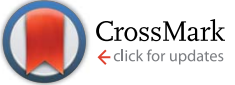

Cite this: RSC Adv., 2017, 7, 3611

\title{
Solvent-free synthesis of polyhydroquinoline derivatives employing mesoporous vanadium ion doped titania nanoparticles as a robust heterogeneous catalyst via the Hantzsch reaction $\dagger$
}

\begin{abstract}
G. B. Dharma Rao, ${ }^{\star a b}$ S. Nagakalyan ${ }^{b}$ and G. K. Prasad*a
Mesoporous vanadium ion doped titania nanoparticles $\left(\mathrm{V}-\mathrm{TiO}_{2}\right)$ were used as a reusable and robust heterogeneous catalyst for one-pot four component synthesis of polyhydroquinoline derivatives via the esteemed Hantzsch reaction using arylaldehyde, $\beta$-ketoester, dimedone and ammonium acetate at $80{ }^{\circ} \mathrm{C}$ under solvent-free conditions as a multi-component synthesis. On the other hand, the catalytic activity of $\mathrm{V}-\mathrm{TiO}_{2}$ was compared with undoped commercial titania nanocatalyst. This protocol was successfully pertinent to a wide range of structurally diverse arylaldehydes with $\beta$-ketoester, dimedone and ammonium acetate to afford the corresponding polyhydroquinoline derivatives. Operational simplicity, short reaction time and satisfactory yields are the key features of this protocol. The catalyst could easily be recycled and reused without observable decrease in catalytic activity.
\end{abstract}

Received 11th November 2016 Accepted 5th December 2016

DOI: $10.1039 / c 6 r a 26664 a$

www.rsc.org/advances

Bearing in mind the considerable applications in the fields

\section{Introduction}

1,4-Dihydropyridines (1,4-DHPs) and polyhydroquinoline (PHQ) derivatives has become a noticeable class of privileged $\mathrm{N}$-heterocyclic compounds and were widely investigated in past decades due to their promising pharmacological and biological activities. ${ }^{1}$ Some of them have antitubercular properties, ${ }^{2}$ anticancer, ${ }^{3}$ neurotropic, ${ }^{4}$ neuropeptide $\mathrm{YY}_{1}$ receptor antagonists, ${ }^{5}$ neuroprotective, ${ }^{6}$ platelet anti-aggregation, ${ }^{7}$ bronchodilating ${ }^{8}$ and antidiabetic activities. ${ }^{9}$ The 1,4-DHPs and PHQ derivatives which are commercially accessible, as analogues of nicotinamide adenine dinucleotide (NADH) coenzymes are extensively used as calcium channel blockers for the treatment of cardiovascular disorder including hypertension, angina and cardiac arrhythmias. ${ }^{10}$ Besides this, the focus on the synthesis of 1,4-DHPs with respect to multidrug resistance (MDR) reversal in tumor cells provided a new aspect to their applications. ${ }^{11}$ By the evidence of the above pharmacological and biological activities, the 1,4-DHPs and PHQ core units have occupied a governing position in medicinal chemistry, which evidently expresses the extraordinary potential of new 1,4-DHP and PHQ analogues as a source of precious drug candidates.

\footnotetext{
${ }^{a}$ Defence Research \& Development Establishment, Jhansi Road, Gwalior 474 002, M.P., India.E-mail: gbdharmarao@gmail.com; gkprasad2001@yahoo.com

${ }^{b}$ Department of Chemistry, Kommuri Pratap Reddy Institute of Technology, Hyderabad - 501 301, TS, India

$\dagger$ Electronic supplementary information (ESI) available: General experimental information, spectral characterization data and copies of ESI-MS and GC-MS spectra of the products. See DOI: 10.1039/c6ra26664a
} of medicinal, bioorganic and synthetic organic chemistry, there has been incredible attention in developing proficient methods for the synthesis of PHQ. Such a medicinally significant 1,4DHPs was initially established by Arthur Hantzsch in 1882 via the reaction of aldehydes with ethyl acetoacetate and ammonia in acetic acid or by refluxing in alcohols more than a century ago. ${ }^{12}$ Though, the yields of the desired products were modest. In addition, a notable number of citations ${ }^{\mathbf{1 3}}$ for the synthesis of PHQ are currently addressed to advances the reaction conditions as maximize the product yield and minimize the reaction time along with deviation in precursors to acquire the polyfunctionalized PHQ. Practically all new advanced technologies have also been contributed in synthesis of 1,4-DHPs such as, microwave-mediated synthesis, ${ }^{14}$ the support of solar thermal energy ${ }^{15}$ ultrasound irradiation, ${ }^{16}$ infrared irradiation, ${ }^{17}$ ionic liquids, ${ }^{18}$ grinding ${ }^{19}$ and metal halides or triflates. ${ }^{20}$ Even supposing most of these processes place ahead individual advantages and some are associated with more than a few of shortcomings such as extend reaction times, expensive/toxic reagents, deadly reaction circumstances, modest-product yields and the use of volatile organic solvents.

The improvement in nanotechnology has lead to an increasing insist for multifunctional materials. Highly ordered mesoporous materials occupied as stupendous catalysts owing to their high surface area and surface functionalities. The physical and chemical properties of mesoporous $\mathrm{V}-\mathrm{TiO}_{2}$ materials depend on their particle size as well as percentage of vanadium ion doped in $\mathrm{TiO}_{2}$ lattice. Smaller sized particles are expected to expose enhanced chemical reactivity because of 


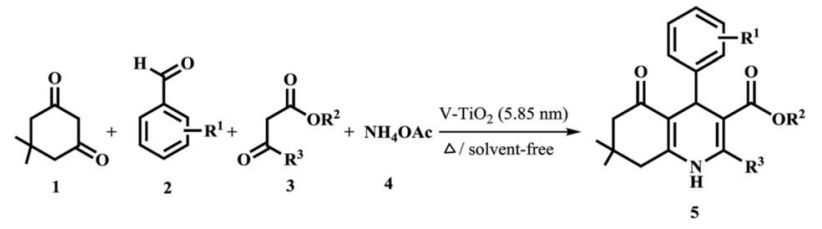

Scheme 1 Poly-functionalized hydroquinoline derivatives via Hantzsch hetero annulations.

their huge surface area to volume ratio, augmented number of surface defect sites. Particle size excessively plays imperative responsibility in dynamics of electron/hole recombination process and influences its catalytic properties.

Moreover, the noxious and volatile nature of many organic solvents used in organic synthesis has posed a grave menace to the environment. Accordingly, protocols that effectively minimize their use are currently the subject of substantial awareness for synthetic chemists. ${ }^{21}$ Furthermore, it is imperative to note that the amalgamation of heterogeneous catalysis with the use of solvent-free conditions stand for an appropriate way in the direction of the so-called ideal synthesis. Nanoparticle $\mathrm{TiO}_{2}$ powerfully catalyzes the conjugate 1,4-addition of indoles to $\alpha, \beta$-unsaturated ketones and 1,2-addition of $\mathrm{Me}_{3} \mathrm{SiCN}$ to carbonyl compounds. ${ }^{22}$ They confirmed the efficiency of $\mathrm{TiO}_{2}$ NPs and attributed it to the enhanced acidic sites and surface area. In this regards and the advantage of enhanced catalytic activity of $\mathrm{TiO}_{2}$ NPs herein, we describe an expeditious, practical and one-pot four component solvent-free synthesis of polyhydroquinoline derivatives via esteemed Hantzsch reaction promoted by $\mathrm{V}-\mathrm{TiO}_{2}$ NPs.

Above and beyond, $\mathrm{TiO}_{2}$ is more steady, copious, non hazardous and inexpensive. For this motive, we have synthesized mesoporous $\mathrm{V}-\mathrm{TiO}_{2}$ materials of nano-size by sol-gel method and characterized them by XRD, TEM, EDX, XPS and FT-IR techniques. In prolongation of our work on new synthetic approaches $^{23}$ and to determine the catalytic application of $\mathrm{V}$ $\mathrm{TiO}_{2}$ (ref. 24) in this communication, we explanation the percentage of vanadium ion doped in $\mathrm{TiO}_{2}$ size dependant application of $\mathrm{V}_{-} \mathrm{TiO}_{2}$ nanoparticles of dissimilar sizes $(6.12 \mathrm{~nm}, 6.45 \mathrm{~nm}, 5.85 \mathrm{~nm}, 6.76 \mathrm{~nm}$, and $11 \mathrm{~nm})$ as reusable robust heterogeneous catalysts for the synthesis of polyfunctionalized hydroquinoline analogues 5a-u (Scheme 1) via Hantzsch hetero-annulation under solvent-free conditions.

\section{Results and discussion}

\subsection{Characterization of $\mathrm{V}-\mathrm{TiO}_{2} \mathrm{NPs}$}

XRD patterns of the synthesized $\mathrm{V}-\mathrm{TiO}_{2}$ catalysts are depicted in Fig. 1. Data depicts peaks at $2 \theta$ values $25.2^{\circ}, 37.8^{\circ}, 48.0^{\circ}, 53.8^{\circ}$, and $62.7^{\circ}$. These peaks can be recognized to the presence of $(10$ 1), ( $\left.\begin{array}{lll}0 & 0 & 4\end{array}\right),\left(\begin{array}{lll}2 & 0 & 0\end{array}\right),\left(\begin{array}{lll}1 & 0 & 5\end{array}\right)$, and ( $\left.\begin{array}{lll}2 & 1 & 5\end{array}\right)$ indices. This XRD pattern demonstrates $2 \theta$ values and relative intensities that match with (JCPDS 21-1272) data of anatase phase of $\mathrm{TiO}_{2}$. No peaks corresponding to oxides of vanadium $\left(\mathrm{V}_{2} \mathrm{O}_{5}\right.$ or $\left.\mathrm{V}_{x} \mathrm{O}_{y}\right)$ are observed even for samples doped with 2 at\% vanadium. This observation indicates the incorporation of vanadium ion into $\mathrm{TiO}_{2}$ lattice.

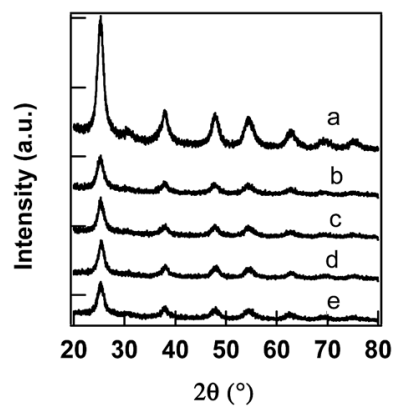

Fig. 1 XRD patterns of (a) $\mathrm{TiO}_{2}$ (b) $0.1 \mathrm{~V}-\mathrm{TiO}_{2}$ (c) $0.25 \mathrm{~V}-\mathrm{TiO}_{2}$ (d) 0.55 $\mathrm{V}-\mathrm{TiO}_{2}$ (e) $2.0 \mathrm{~V}-\mathrm{TiO}_{2}$ nanocatalysts.

The data also illustrated peak broadening in XRD pattern indicating the formation of crystallites with very small size. The crystallite sizes of $\mathrm{V}-\mathrm{TiO}_{2}$ catalysts were calculated by Scherrer equation and they were found to be $6.12,6.45,5.85,6.76 \mathrm{~nm}$ respectively for $0.1 \mathrm{~V}-\mathrm{TiO}_{2}, 0.25 \mathrm{~V}-\mathrm{TiO}_{2}, 0.55 \mathrm{~V}-\mathrm{TiO}_{2}$ and $2 \mathrm{~V}-$ $\mathrm{TiO}_{2}$ respectively. The crystallite size of bare $\mathrm{TiO}_{2}$ nanoparticles $\left(\mathrm{TiO}_{2} \mathrm{NPs}\right)$ was found to be $11 \mathrm{~nm}$.

TEM was used to determine the crystallite sizes of $\mathrm{TiO}_{2}$ particles synthesized by modified sol-gel method followed by hydrothermal treatment. TEM images of both doped (0.1 V$\mathrm{TiO}_{2}$ ) and bare ( $\mathrm{TiO}_{2}$ NPs) samples are shown in Fig. 2(a) and (b). No noteworthy differences are observed when the images of $\mathrm{V}-\mathrm{TiO}_{2}$ and $\mathrm{TiO}_{2}$ NPs samples are compared. TEM images visibly indicate that particles have homogeneity and quite small size. It can be seen from the images that particles are established to be embedded in the agglomerates with crystallite sizes around 6 to $11 \mathrm{~nm}$ which are found to be comparable to average crystallite sizes determined from XRD data.

Hence keeping these particulars in observation, in this communication, we were concerned in attaining the solvent-free synthesis of polyhydroquinoline derivatives using catalytic amount of $\mathrm{V}-\mathrm{TiO}_{2}$ nanoparticles. Our exploration started with an optimization study for the union between dimedone (1), $p$ methoxybenzaldehyde (2c), ethyl acetoacetate (3) and ammonium acetate (4) (Table 4, entry 3 ) in the presence of a catalytic amount of various size $\mathrm{V}-\mathrm{TiO}_{2} \mathrm{NPs}$ as well as commercial $\mathrm{TiO}_{2} \mathrm{NPs}$. The best result was observed when dimedone (1), $p$-methoxybenzaldehyde (2c), ethyl acetoacetate (3) and ammonium acetate

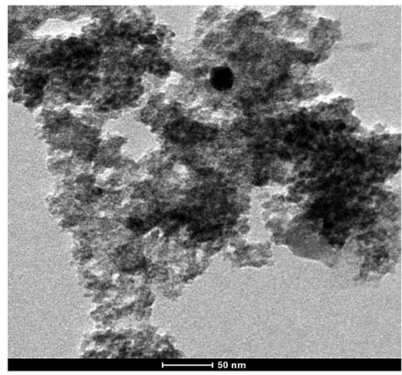

(a)

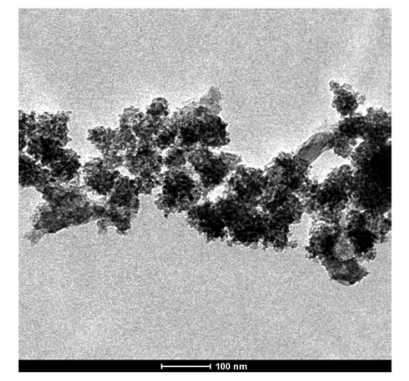

(b)
Fig. 2 TEM images of (a) $\mathrm{TiO}_{2} \mathrm{NPs}$ (b) $0.1 \mathrm{~V}-\mathrm{TiO}_{2} \mathrm{NPs}$. 
(4) were used in the mole ratio $1: 1: 1: 2$ employed by the catalytic amount of $\mathrm{V}-\mathrm{TiO}_{2}$ NPs of $5.85 \mathrm{~nm}$ size at $80{ }^{\circ} \mathrm{C}$ under solventfree conditions, to afford the resulting ethyl 4-(4-methoxyphenyl)2,7,7-trimethyl-5-oxo-1,4,5,6,7,8-hexahydroquinoline-3-carboxylate (5c) (Table 4, entry 3 ) in 90\% yield without any other bi-products. This four component union reaction proceeded efficiently at temperature $\left(80^{\circ} \mathrm{C}\right)$ with high yield under solvent-free reaction condition and shown in Fig. 3.

From the above considerations, we examine the different catalytic concentrations for the solvent-free synthesis of polyhydroquinoline derivatives using $\mathrm{V}-\mathrm{TiO}_{2}$ NPs with $5.85 \mathrm{~nm}$ particle size as heterogeneous catalyst at $80{ }^{\circ} \mathrm{C}$. To study the feasibility of the different catalytic concentrations, the reaction of dimedone (1), $p$-methoxybenzaldehyde (2c), ethyl acetoacetate (3) and ammonium acetate (4) was selected as model reactants for the synthesis of corresponding polyhydroquinoline (Table 4, entry 3 ) and fixed the reaction time to $12 \mathrm{~min}$. However, among all the catalytic concentrations, it was observed that, $2.0 \mathrm{~mol} \%$ of $\mathrm{V}-\mathrm{TiO}_{2} \mathrm{NPs}$ of $5.85 \mathrm{~nm}$ size was found to be the most effective for the reaction of four component Hantzsch reaction with respect to yield as tabulated in Table 1.

During exploratory reactions, we studied the fourcomponent condensation reaction of model reactants dimedone (1), $p$-methoxybenzaldehyde (2), ethyl acetoacetate (3) and ammonium acetate (4) in the mole ratio $=1: 1: 1: 2$ under different addressed catalytic conditions for $12 \mathrm{~min}$ as reaction time. However, $\mathrm{V}-\mathrm{TiO}_{2}$ powerfully catalyzed the reaction and afford high yield of the corresponding PHQ product (Table 2, entry 4).

The possibility of optimized reaction conditions was further extended to the synthesis of more functionalized polyhydroquinoline derivatives and experiments were performed by making use of wide range of arylaldehyde bearing variety of functional groups. As shown in the Table 2, the desired ring closure annulations of polyhydroquinoline (PHQ) ring was obtained with mono, di (Table 4, entries 6, 12 and 16) and even trisubstituted (Table 4, entries 8 and 19) arylaldehydes in good to excellent yields (70-92\%). Furthermore, hetero arylaldehydes such as furfural and pyridine-3-carboxyaldehyde (Table 4, entries 14 and 15) also afforded the target products in good yields $(62-78 \%)$ under the same reaction conditions. In all these

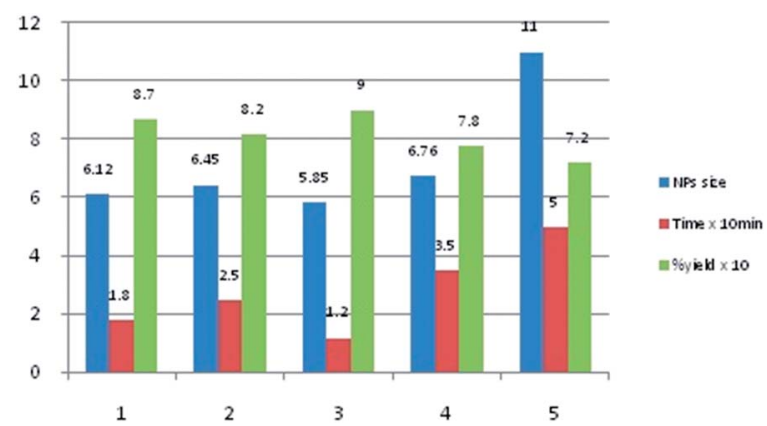

Fig. 3 Effect of $\mathrm{V}-\mathrm{TiO}_{2} \mathrm{NPs}$ size for the solvent-free synthesis of polyhydroquinoline derivatives.
Table 1 Effect of catalytic concentration for the solvent-free synthesis of polyhydroquinoline using $\mathrm{V}-\mathrm{TiO}_{2} \mathrm{NPS}$

\begin{tabular}{llll}
\hline Entry & $\begin{array}{l}\text { Catalytic conc. } \\
(\mathrm{mol} \%)\end{array}$ & $\begin{array}{l}\text { Reaction time } \\
(\mathrm{min})\end{array}$ & \% yield \\
\hline 1 & 0.5 & 12 & 45 \\
2 & 1.0 & 12 & 62 \\
3 & 1.5 & 12 & 76 \\
4 & 2.0 & 12 & 90 \\
5 & 2.5 & 12 & 81
\end{tabular}

Table 2 Effect of addressed catalysts for the solvent-free synthesis of $\mathrm{PHQ}^{a}$

\begin{tabular}{lll}
\hline S. no. & Catalyst $^{\text {ref. }}$ & \% yield \\
\hline 1 & $p$-TSA & 72 \\
2 & $\mathrm{I}_{2}($ ref. $13 c)$ & 35 \\
3 & $\mathrm{TiO}_{2}($ ref. 13a) & 42 \\
4 & $\mathrm{~V}-\mathrm{TiO}_{2}$ & 90 \\
5 & None & NR
\end{tabular}

${ }^{a}$ Reaction conditions: the mixture of 1 (1.0 mmol), 2 (1.0 mmol), 3 (1.0 $\mathrm{mmol})$ and $4(2.0 \mathrm{mmol})$ at $80^{\circ} \mathrm{C}$ using reported catalysts under solventfree condition for $12 \mathrm{~min}$. $\mathrm{NR}=$ no result.

cases, the reactions were clean and the products were obtained with simple work-up in good to excellent yields. Compared to reports which were addressed in the literature, this method has numerous advantages, which include operational simplicity, short reaction time and satisfactory yields, does not require chromatographic separation and wider substrate scope are the key features of this protocol. The catalyst could easily be recycled and reused without observable decrease in catalytic activity.

\subsection{Reusability of the catalyst}

In order to explore the recyclability of catalyst, it was filtered off at the end of the reaction from the reaction mixture and washed with mixture of hot ethanol and water, dried and activated at $300{ }^{\circ} \mathrm{C}$ for $2 \mathrm{~h}$. Catalyst was and reused as such for subsequent experiments (up to four cycles) under the similar reaction conditions and the change in their catalytic activity was studied w.r.t time and \% yield. The recyclability of catalyst was verified

Table 3 Recyclability of the $\mathrm{V}-\mathrm{TiO}_{2} \mathrm{NPs}$ for the synthesis of polyhydroquinoline $(\text { Table } 4,5 c)^{a}$

\begin{tabular}{lll}
\hline Entry & Cycle & $\%$ yield $^{b}$ \\
\hline 1 & Cycle 1 & 90 \\
2 & Cycle 2 & 86 \\
3 & Cycle 3 & 80 \\
4 & Cycle 4 & 72
\end{tabular}

${ }^{a}$ Reaction conditions: the mixture of 1 ( $\left.1.0 \mathrm{mmol}\right), 2$ (1.0 mmol), 3 (1.0 $\mathrm{mmol})$ and $4(2.0 \mathrm{mmol})$ at $80{ }^{\circ} \mathrm{C}$ using $\mathrm{V}-\mathrm{TiO}_{2}$ NPs of $5.85 \mathrm{~nm}$ size under solvent-free condition for 12 min. ${ }^{b}$ Yields after consecutive cycles. 
Table $4 \mathrm{~V}-\mathrm{TiO}_{2} \mathrm{NPs}$ of $5.85 \mathrm{~nm}$ size promoted synthesis of polyhydroquinoline derivatives ${ }^{a}$

\begin{tabular}{|c|c|c|c|c|c|c|c|c|}
\hline Entry & $\mathrm{R}$ & $\mathrm{R}^{1}$ & $\mathrm{R}^{2}$ & Time (min) & Product & Yield $^{b}(\%)$ & $\mathrm{Mp}\left({ }^{\circ} \mathrm{C}\right)$ & Reported mp $\left({ }^{\circ} \mathrm{C}\right)$ \\
\hline 1 & $\mathrm{H}-$ & $\mathrm{CH}_{3}$ & OEt & 10 & $5 a$ & 85 & $203-204$ & $202-204$ \\
\hline 2 & $4-\mathrm{CH}_{3}^{-}$ & $\mathrm{CH}_{3}$ & OEt & 12 & $5 \mathbf{b}$ & 90 & $261-262$ & $260-261$ \\
\hline 4 & 4-Cl- & $\mathrm{CH}_{3}$ & OEt & 14 & $5 d$ & 82 & $245-246$ & $245-246$ \\
\hline 5 & $4-\mathrm{NO}_{2-}^{-}$ & $\mathrm{CH}_{3}$ & OEt & 15 & $5 e$ & 80 & $243-244$ & $242-244$ \\
\hline 6 & $2,4-\mathrm{Cl}_{2}^{-}$ & $\mathrm{CH}_{3}$ & OEt & 12 & $5 f$ & 74 & $242-243$ & $241-243$ \\
\hline 9 & $2-\mathrm{NO}_{2-}^{-}$ & $\mathrm{CH}_{3}$ & OEt & 15 & $5 i$ & 70 & $206-207$ & $206-208$ \\
\hline 10 & $3-\mathrm{NO}_{2}^{-}$ & $\mathrm{CH}_{3}$ & OEt & 14 & $5 \mathbf{j}$ & 82 & $178-179$ & $177-178$ \\
\hline 11 & 4 -F- & $\mathrm{CH}_{3}$ & OEt & 10 & $5 \mathbf{k}$ & 94 & $185-186$ & $184-186$ \\
\hline 12 & $3,4-\left(\mathrm{OCH}_{3}\right)_{2^{-}}$ & $\mathrm{CH}_{3}$ & OEt & 20 & 51 & 88 & 196-198 & 198-199 \\
\hline 13 & $4-\mathrm{N}\left(\mathrm{CH}_{3}\right)_{2^{-}}$ & $\mathrm{CH}_{3}$ & OEt & 15 & $5 \mathrm{~m}$ & 90 & $262-263$ & $263-264$ \\
\hline 14 & 2-Furyl & $\mathrm{CH}_{3}$ & OEt & 12 & $5 n$ & 65 & $247-248$ & $246-248$ \\
\hline 19 & $3,4,5-\left(\mathrm{OCH}_{3}\right)_{3^{-}}$ & $\mathrm{CH}_{3}$ & OMe & 20 & $5 s$ & 72 & $220-221$ & $220-224$ \\
\hline 20 & $4-\mathrm{N}\left(\mathrm{CH}_{3}\right)_{2^{-}}$ & $\mathrm{CH}_{3}$ & OMe & 12 & $5 t$ & 78 & $257-258$ & $258-260$ \\
\hline 21 & $3-\mathrm{Br}-$ & $\mathrm{CH}_{3}$ & OEt & 16 & $5 \mathbf{u}$ & 82 & $230-232$ & $234-236$ \\
\hline
\end{tabular}

${ }^{a}$ Reaction conditions: $1(1.0 \mathrm{mmol}), 2(1.0 \mathrm{mmol}), 3(1.0 \mathrm{mmol})$ and $4(2.0 \mathrm{mmol})$ at $80{ }^{\circ} \mathrm{C}$ using $\mathrm{V}-\mathrm{TiO}_{2} \mathrm{NPs}$ of $5.85 \mathrm{~nm}$ size under solvent-free condition. ${ }^{b}$ Isolated yield.

on the reaction of dimedone (1), $p$-methoxybenzaldehyde (2c), ethyl acetoacetate (3) and ammonium acetate (4) (Table 4, entry 3) was selected as model reactants and fixed the reaction time to $12 \mathrm{~min}$ to afford the corresponding polyhydroquinoline in 90 , 86,80 and $72 \%$ yields over four cycles (Table 3 ). It was noticed that yields of the product remained comparable in these experiments, and thereby pointing the reusability of the catalyst without any significant loss in catalytic activity.

On the basis of the above explanations and the literature precedents, the possible mechanistic path for the synthesis of polyhydroquinoline (PHQ) derivatives is given in Scheme 2. The used metal oxides species contains Lewis acid sites and

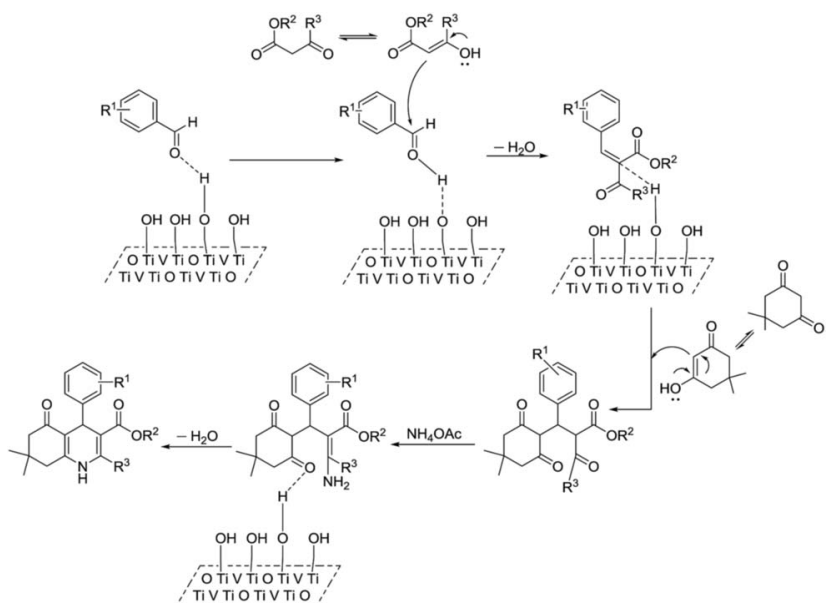

Scheme 2 Proposed mechanism for the synthesis of polyhydroquinoline derivatives.
Bronsted acid sites in addition to basic surface sites. Surface of $\mathrm{V}-\mathrm{TiO}_{2}$ nanoparticles was found to be basic in nature. Further incorporation of vanadium transition metal into $\mathrm{TiO}_{2}$ lattice would increase the number of Lewis acid sites, Bronsted acid sites and other defects which play main role in increasing the reactivity of metal oxides as heterogeneous catalyst. The interaction between arylaldehyde with the acidic sites of $\mathrm{V}-\mathrm{TiO}_{2} \mathrm{NPs}$ catalyst surface generated the more electrophilic carbon center followed by the nucleophilic attack of $\beta$-ketoester followed by dimedone to give reactive adduct intermediate. The resulting intermediate undergoes a intramolecular cyclization in presence of $\mathrm{NH}_{4} \mathrm{OAc}$ affording the corresponding desired polyhydroquinoline followed by the elimination of water molecule.

\section{Experimental details}

\subsection{Materials}

Vanadyl acetylacetonate, titanium tetraisopropoxide (TTIP) were procured from Acros organics, UK. Dichloromethane, ethanol and acetonitrile were obtained from E. Merck India Ltd. Arylaldehydes, methyl/ethyl $\beta$-ketoester, dimedone and ammonium acetate were purchased from Sigma-Aldrich, India. Chemicals purchased from Across, Sigma-Aldrich and Merck (India) were used without further purification.

\subsection{Preparation of vanadium ion doped $\mathrm{TiO}_{2}$ nanoparticles (V-TiO 2 NPs)}

$\mathrm{V}-\mathrm{TiO}_{2}$ NPs of various dimensions were synthesized in our laboratory by modified sol-gel hydrolysis of titanium(Iv) isopropoxide (TTIP) subsequently hydrothermal treatment 
procedure as follows: initially, the mixture of deionized water and ethanol were placed at room temperature with constant vigorous stirring. To this mixture add TTIP drop wise which is dissolved in anhydrous ethanol. As the observed gel was relocated into Teflon lined autoclave and heated at $80{ }^{\circ} \mathrm{C}$ for $24 \mathrm{~h}$. The accomplished solid was dried at room temperature and finally tagged as bare $\mathrm{TiO}_{2}$ nanoparticles ( $\left.\mathrm{TiO}_{2} \mathrm{NPs}\right)$. At last, the obtained $\mathrm{TiO}_{2}$ NPs were washed with excess of ethanol to eradicate organic moieties. $^{25}$ In the same way, metal ion dopants were incorporated through adding appropriate amounts of vanadyl acetylacetonate into distilled water foregoing to the hydrolysis of TTIP. By varying concentration of vanadyl acetylacetonate, diverse nanoparticles were synthesized. The nanoparticles were tagged as $0.1 \mathrm{~V}-\mathrm{TiO}_{2}(0.1$ at $\% \mathrm{~V}$ in $\left.\mathrm{TiO}_{2}\right), 0.25 \mathrm{~V}-\mathrm{TiO}_{2}\left(0.25\right.$ at\% $\mathrm{V}$ in $\left.\mathrm{TiO}_{2}\right), 0.55 \mathrm{~V}-\mathrm{TiO}_{2}(0.55$ at $\% \mathrm{~V}$ in $\mathrm{TiO}_{2}$ ) and $2.0 \mathrm{~V}-\mathrm{TiO}_{2}\left(2.0 \mathrm{at} \% \mathrm{~V}\right.$ in $\left.\mathrm{TiO}_{2}\right)$.

\subsection{Catalyst characterization techniques}

Powder X-ray diffraction (XRD) patterns of the synthesized samples were recorded on X'Pert Pro Diffractometer of $\mathrm{M} / \mathrm{s}$ Panalytical, Netherlands make using $\mathrm{Cu} \mathrm{K} \alpha$ radiation. Transmission electron microscopy (TEM) measurements were done on Tecnai transmission electron microscope of FEI make. Samples were suspended in $30 \mathrm{~mL}$ of acetone, and the suspension was sonicated for $30 \mathrm{~min}$. After that, suspension was placed on carbon coated copper grids of $3 \mathrm{~mm}$ dia and dried at room temperature prior to the analysis. Nitrogen adsorption measurements were done on ASAP 2020 surface area analyzer of Micrometrics, USA. FT-IR measurements were done as $\mathrm{KBr}$ pellets on Perkin Elmer, USA instrument. X-ray photoelectron spectroscopy (XPS) data was recorded on KRATOS AXIS 165 instrument. $\mathrm{TiO}_{2}, \mathrm{~V}-\mathrm{TiO}_{2}$ nanoparticles are confirmed by Energy-Dispersive X-ray spectroscopy (EDX) spectrum that reveals the presence of $\mathrm{Ti}, \mathrm{V}$ and $\mathrm{O}$ elements. Au and $\mathrm{C}$ signals could be due to gold coating and carbon film supporting the specimen during SEM observation.

\subsection{Catalytic activity: synthesis of polyhydroquinoline derivatives via Hantzsch reaction}

To a mixture of methyl/ethyl acetoacetate $(1.0 \mathrm{mmol})$, dimedone $(1.0 \mathrm{mmol})$, arylaldehyde $(1.0 \mathrm{mmol})$ and ammonium acetate $(2.0 \mathrm{mmol})$, catalytic amount $(2.0 \mathrm{~mol} \%)$ of $\mathrm{V}-\mathrm{TiO}_{2}$ nanoparticle was added at room temperature under stirring. The reaction mixture was heated on oil bath at $80^{\circ} \mathrm{C}$. The reaction advancement was monitored by TLC. After the completion of reaction, it was cooled to room temperature and the resultant reaction mixture was washed with brine and extracted with ethyl acetate. The catalyst was separated out by filtration from the extraction mixture. Organic layer was separated, dried over anhydrous sodium sulfate and concentrated under reduced pressure. The crude product was then purified by re-crystallization from hot ethanol and water to afford 1,4-dihydroquinoline derivatives in high yield. The structures of the products were confirmed from physical and spectroscopic data (IR and ${ }^{1} \mathrm{H}$ NMR) in comparison with the literature data.

\section{Conclusion}

In conclusion, a simple, efficient and environmentally benign procedure has been developed using mesoporous vanadium ion doped titania nanoparticles $\left(\mathrm{V}-\mathrm{TiO}_{2}\right)$ as robust heterogeneous nanocatalyst for the synthesis of polyhydroquinoline derivatives via esteemed Hantzsch reaction of arylaldehyde, $\beta$-ketoester, dimedone and ammonium acetate at $80{ }^{\circ} \mathrm{C}$ under solvent-free conditions as multi-component synthesis. This protocol was successfully pertinent to a wide range of structurally diverse arylaldehydes with $\beta$-ketoester, dimedone and ammonium acetate to afford the corresponding polyhydroquinoline derivatives. The advantages of performing the Hantzsch reaction in the presence of $\mathrm{V}-\mathrm{TiO}_{2} \mathrm{NPs}$ as catalyst can be summarized as follows: (1) use of a safe, non-volatile, non-corrosive and easily handled $\mathrm{V}-\mathrm{TiO}_{2} \mathrm{NPs}$; (2) recovery of $\mathrm{V}-\mathrm{TiO}_{2} \mathrm{NPs}$ at the end of the reactions by simple filtration and washing; (3) desired products are obtained in admirable yields under mild reaction conditions; and (4) the reactions are carried out under solvent-free conditions with economic benefits. Excellent reusability of the catalyst and ease of isolation of product are the other added advantages that make this approach an attractive alternative for the synthesis of these polyhydroquinoline derivatives.

\section{Acknowledgements}

Authors express deep sense of gratitude to Ravi K. Gujjula, Principal, KPRIT, Hyderabad and also special thanks to IISER, Bhopal.

\section{Notes and references}

1 R. Shan, C. Velazquez and E. E. Knaus, J. Med. Chem., 2004, 47, 254-261.

2 P. S. Eharkar, B. Desai, H. Gaveria, B. Varu, R. Loriya, Y. Naliapara, A. Shah and V. M. Kulkarni, J. Med. Chem., 2002, 45, 4858-4867.

3 T. Tsuruo, H. Iida, M. Nojiri, S. Tsukagoshi and Y. Sakurai, Cancer Res., 1983, 43, 2905-2910.

4 A. Krauze, S. Germane, O. Eberlins, I. Sturms, V. Klusa and G. Duburs, Eur. J. Med. Chem., 1999, 34, 301-310.

5 G. S. Poindexter, M. A. Bruce, J. G. Breitenbucher, M. A. Higgins, S. Y. Sit, J. L. Romine, S. W. Martin, S. A. Ward, R. T. McGovern, W. Clarke, J. Russell and I. Antal-Zimanyi, Bioorg. Med. Chem., 2004, 12, 507-521.

6 V. Klusa, Drugs Future, 1995, 20, 135-138.

7 R. G. Bretzel, C. C. Bollen, E. Maeser and K. F. Federlin, Am. J. Kidney Dis., 1993, 21, 53-64.

8 R. W. Chapman, G. Danko and M. I. Siegels, Pharmacology, 1984, 29, 282-291.

9 A. K. Ogawa, C. A. Willoughby, R. Bergeron, K. P. Ellsworth, W. M. Geissler, R. W. Myer, J. Yao, G. Harris and K. T. Chapman, Bioorg. Med. Chem. Lett., 2003, 13, 34053408.

10 Comprehensive Medicinal Chemistry, Ed. J. C. Emmet, Pergamon Press, Oxford, 1990, ch. 14.1, vol. 3. 
11 S. Tasaka, H. Ohmori, N. Gomi, M. Iino, T. Machida, A. Kiue, S. Naito and M. Kuwano, Bioorg. Med. Chem. Lett., 2001, 11, 275-277.

12 A. Hantzsch, Chem. Ber., 1881, 14, 1637-1638.

13 (a) M. Tajbakhsh, E. Alaee, H. Alinezhad, M. Khanian, F. Jahani, S. Khaksar, P. Rezaee and M. Tajbakhsh, Chin. J. Catal., 2012, 33, 1517-1522, references there in; (b) M. Nasr-Esfahani, M. Montazerozohori and R. Raeatikia, Maejo Int. J. Sci. Technol., 2014, 8, 32-40; (c) J. D. Akbari, S. D. Tala, M. F. Dhaduk and H. S. Joshi, ARKIVOC, 2008, 126-135.

14 S. J. Tu, J. F. Zhou, X. Deng, P. J. Cai, H. Wang and J. C. Feng, Chin. J. Org. Chem., 2001, 21, 313.

15 R. A. Mekheimer, A. A. Hameed and K. U. Sadek, Green Chem., 2008, 10, 592.

16 J.-Y. He, H.-Z. Jia, Q.-G. Yao, S.-J. Liu, H.-K. Yue, H.-W. Yu and R.-S. Hu, Ultrason. Sonochem., 2015, 22, 144-148.

17 R. Gómez-Pliego, R. Osnaya, I. Zamora, B. Velasco-Bejarano, G. Arroyo, E. Ramírez-San Juan, J. Trujillo, F. Delgado and R. Miranda, J. Mex. Chem. Soc., 2007, 51, 181-184.

18 X. Y. Zhang, Y. Z. Li, X. S. Fan, G. R. Qu, X. Y. Hu and J. J. Wang, Chin. Chem. Lett., 2006, 17, 150.
19 S. Kumar, P. Sharma, K. K. Kapoor and M. S. Hundal, Tetrahedron, 2008, 64, 536.

20 L. M. Wang, J. Sheng, L. Zhang, J. W. Han, Z. Y. Fan, H. Tian and C. T. Qian, Tetrahedron, 2005, 61, 1539.

21 J. H. Clark and C. N. Rhodes, Clean Synthesis using Porous Inorganic Solid Catalysts and Supported Reagents, Royal Society of Chemistry, UK, 1st edn, 2000.

22 B. M. Khadikar, V. G. Gaikar and A. A. Chitnavis, Tetrahedron Lett., 1995, 36, 8083.

23 (a) G. B. Dharma Rao, B. N. Acharya, S. K. Verma and M. P. Kaushik, Tetrahedron Lett., 2011, 52, 809-812; (b) G. B. Dharma Rao, B. Anjaneyulu and M. P. Kaushik, Tetrahedron Lett., 2014, 55, 19-22; (c) G. B. Dharma Rao, B. N. Acharya and M. P. Kaushik, Tetrahedron Lett., 2013, 54, 6644-6647.

24 (a) X. X. Yang, C. Cao, K. Hohn and L. Erickson, J. Catal., 2007, 252, 296; (b) P. V. R. K. Ramacharyulu, J. Praveen Kumar, G. K. Prasad, G. Pranav Kumar and K. Dwivedi, Adv. Porous Mater., 2013, 1, 1; (c) S. T. Martin, C. L. Morrison and M. R. Hoffmann, J. Phys. Chem., 1994, 98, 13695.

25 Z. Zhang, C. C. Wang, R. Zakaria and J. Y. Wing, J. Phys. Chem. B, 1998, 102, 10871. 